\title{
Guendalina Graffigna, Serena Barello, Stefano Triberti Giving (Back) a Role to Patients in the Delivery of Healthcare Services: Theoretical Roots of Patient Engagement
}

\begin{abstract}
As the concept of patient engagement is increasingly accepted and valued by both academics and policy makers, the number of terms and definitions used to describe the active role of patients across various healthcare settings and health disciplines has increased, often leading to semantic confusion among healthcare professionals, managers, and policy makers. This chapter examines the literature on the concept of patient engagement and related concepts, including definitions and theoretical perspectives. The chapter is conceived as a "glossary" of conceptualizations related to the active role of patients in their healthcare journey. Based on this theoretical review, it will be easier to understand the value and the applicability of the patient engagement concept. More specifically, patient engagement may be viewed as an umbrella term that qualifies the systemic relation that occurs between the "supply" and the "demand" of healthcare - at different levels and in different situations. Considering this meaning, patient engagement is a broad term which incorporates the other terms, such as patient adherence, patient compliance, self-management, patient involvement, patient participation, shared decision-making, patient activation, and patient's technology engagement, which are more traditionally used to denote the active role of patients in their care, as discussed in this chapter.
\end{abstract}

Keywords: Patient engagement; Patient Adherence, Patient Compliance, SelfManagement, Patient Involvement, Patient Participation, Shared Decision Making, Patient Activation, Patient's Technology Engagement

\section{Introduction}

This chapter is a "glossary" of the main recurrent concepts related to patients' participative role in health and care management.

Since the epochal turning point promoted by the patient centered approach to medicine (Stewart, 2001), many theories about how the patients can be involved in the clinical process have been developed. Furthermore, several concepts and terms are often used synonymously to indicate the active role of patients in the healthcare process.

In our opinion, to concretely innovate healthcare in the direction of patient engagement, it is fundamental to clarify the existing conceptualizations and define what may be the overlaps and differences between the concept of patient engagement and other related concepts. 
This chapter, after introducing the Participatory Medicine paradigm and its pivotal role in enhancing healthcare professionals and managers' sensibility towards the importance of modifying healthcare practices based on patients' perspectives, will offer a deep discussion of the most important (and recurrent) concepts related to the patients' role in the healthcare process. In particular, the chapter will deal with the concepts of: patient adherence, patient compliance, self-management, patient involvement, patient participation, shared decision-making, patient activation, and patients' technological engagement. In particular, this chapter will provide a review of the most up-to-date definitions of each of those concepts and discuss their relations and overlaps with the more recent concept of patient engagement.

The chapter will end by synthesizing the conceptual "boarders" of the patient engagement concept, its aspects of innovativeness and its potential for medical practice.

\section{Historical Milestones in the Development of the Concept of Patient Engagement: The Tradition of Par- ticipatory Healthcare}

We are currently in the midst of one of the most rapid and profound shifts in the history of medicine. When many of today's physicians were still in school, most patients had little or no access to detailed information about their health conditions. The internet was not available and medical libraries were off limits. Over the span of a few years, patients gained access to more medical information, easily accessible through portable smart phone devices, than the late-20th-century Surgeons General had direct access to. The balance of power is shifting, and the amount of health data is exploding. Change is afoot. Participatory medicine is a movement in which networked patients shift from being mere consumers to being responsible drivers of their health and in which providers encourage and value them as full partners (Dyson, 2009; Kabat-Zinn, 2000; Weitzel, et al., 2009).

In the framework of Participatory Medicine, many conceptualizations of the potential active role of patients do exist. Let's see them in detail.

\section{Distinguishing the Concept of Engagement from Other Closely Related Concepts}

It is fundamental to understand the innovative value of the concept of patient engagement and its relationships with other concepts existing in the medical and psychological literature. Indeed, the term patient engagement evokes other terms, which are 
closely linked to it, such as patient compliance, patient adherence, patient empowerment, patient activation, patient involvement, patient participation (Menichetti et al. 2015), shared decision-making, and patient's technological engagement (Barello et al., 2014).

In the next section, we will offer a definition of each of these concepts and will discuss their conceptual relationships with the concept of patient engagement.

\subsection{Involvement, Participation, and Shared Decision-Making}

In the last decade, the ability to involve the patient in his/her care process and collaborate with the health professionals (the physician in particular) in the process of medical consultation has been recognized as one of the primary objectives of improving the quality of health services (Entwistle and Watt, 2006).

The scientific literature on the topic offers a wide variety of terms to describe this objective. The main terms are involvement, participation, and shared decisionmaking. However, there is not a unified vision, nor are there shared guidelines to apply the concept to the real contexts. Moreover, the "involvement" and "participation" terms seem to be used interchangeably in the scientific debate (Gallant et al., 2002; Thompson, 2007).

Considering semantic opacity, the two concepts of involvement and participation appear to be used only when referring to the precise moment of the negotiation of clinical decisions, that is, when a dyadic communication takes place between the patient and the clinician. Indeed, the literature conceives and measures the patient's involvement/participation considering the medical consultation between an "expert" actor (usually the physician) and a "non-expert" one (the patient).

Despite this, it is possible to note that two main theoretical conceptions still dominate the debate. The main difference between the two is related to the level to which the concepts are analyzed (Entwistle and Watt, 2006). The first one, which is psychological, focuses on the subjective dimensions of the patient involved in the medical consultation. Moreover, it is interested in identifying emotional and cognitive factors that can foster the active participation of the patient in clinical decisionmaking. These factors are often related to the concept of "health literacy" (Marteau and Dormandy, 2001; O’Connor, 2003).

The second theoretical tradition, the medical one, focuses on the clinical and relational competences of the physician, which are needed to involve the patient in the clinical decisions. In this sense, communicative and interpersonal abilities are conceived as the main factors fostering or preventing shared decision-making in the care process (Charles, Gafni, and Whelan 1997; 1999).

The link among the concepts of "involvement", "participation", and "shared decision making" engagement is evident, since much of the literature is interested in understanding the active role of the patient in the care process. At the same time, it is 
clear that these terms represent different levels of the analysis of the communication between the supply and the demand for health services.

As mentioned previously, the concepts of "involvement" and "participation" are fundamentally related to the dyadic communication between the clinician and the patient. Moreover, they come out of a compensatory effort to modify the implicit asymmetry of the medical decision-making process. Indeed, the "expert" clinician often appears to take a paternalistic approach to the clinical decision-making, and he/she is usually recognized as the sole holder of the better therapeutic choice. The authors who study the concepts of "involvement" and "participations" sustain that a greater democratization of the decision-making process is needed. In this sense, the clinicians should consider the personal needs and expectations of the client/patient while providing health services.

The concept of "engagement" refers to a wider communicational context. Accordingly, the medical consultation constitutes only one of the possible levels of the analysis of the supply and demand for health services. In other words, an "engaged" patient is not only a patient able to actively participate in the clinical decision making, but also a patient able to activate the global healthcare system; to utilize the care and disease management offered by the conventional organizational contexts present in the territory; to promote new forms of assistance (being themselves supported by new technologies or not); and to generate them from a non-expert context of care. Doing this, the engaged patient is able to virtuously interface with the expert system that provides health services. An interesting example in this direction are the patients who decide to promote their own health rights at social/political levels or the patients who fund associations in order to help other people with similar health conditions and their caregivers.

\subsection{Compliance and Adherence}

The literature that studies the modalities to which the patients manage medical prescriptions and their relationship with the system that provides them often use the terms "compliance" and "adherence". In general, they refer to the patients' adaptive behaviors when they follow the medical prescriptions.

Despite this, the two concepts seem to have different meanings in the scientific debate. Precisely, the term "compliance" comes from the Latin cumplere, which means "to adapt one's behavior to another's desire, rule, or need" (Oxford English Dictionary, 2010), and it is used to describe a conduct of the patient that responds to a coercion by the "expert” figure (usually the physician) (Haynes \& Sackett, 1979; Fletcher, 1989). This concept is based on a paradigm that comes from a disease-centered medicine. In this sense, the physician is considered the only expert of the pathology. For this reason, he/she is also in a dominant position of power in the healing relationship. It is easy to see that this concept implies the impossibility of a real exchange between 
the patient and the system that provides the health services. The relationship with the physician is relentlessly unidirectional.

The physician not only shows a paternalistic approach towards the patient while managing the pathology and providing prescriptions to be strictly followed, but also has the task of judging the behavior of the patient as either correct or incorrect (Playle \& Keeley, 1998). Indeed, the "compliance” is characterized by the patient's attitude towards doing what he/she has to do, adapting his/her own life to the physician's indications. Consequently, the compliant patient is characterized by a passive/dependent attitude, that is, he/she is completely subservient to the health professional (Evangelista, 1999).

The "adherence" term comes from the Latin adherere, which means to be "attached, near" (Pianigiani, 1988) and is more related to a patient centered paradigm. In this case, the main objective to be pursued is a care system in which the patient is a fundamental actor and partner of the health professionals in the construction of adequate responses to his/her demand for care (Anderson, 2002; Stewart, 2001). With this paradigm in mind, those who provide health services need to support autonomy in the patients, which is a key factor in improving the system, in terms of both the quality of life and reduction of costs (DiMatteo, 2004; Thorpe, 2005). The main difference between the terms "compliance" and "adherence" is that the second is more open to an active involvement of the patient in the communication exchange with the physician in order to make decisions about the care plans. In this sense, the active participation of the patient should be promoted. Moreover, he/she is seen as a fundamental actor in the management of his/her own health and in the communicational relationship with the medic.

Indeed, the concepts of "compliance" and "adherence" reveal a vision of the client/patient to healthcare system relationship, which is still limited to the dyadic communication with the physician. Moreover, a passive approach to care still shines through these two concepts, since both of them imply a relational hierarchy in which the expert physician provides life rules for the non-expert patient, in which the competence of the patient regarding negation is poorly considered. Indeed, discussing the terms "adherence" or "compliance" means referring to a value judgment of the physician regarding a patient, who can be more or less "good" in their responses to the physician's judgments and prescriptions.

The patient engagement concept goes beyond the mere evaluation of the patient's behaviors and attitudes in accepting or disregarding the physician's prescriptions, although it may be adopted in order to foster adherence/compliance. Moreover, the concept of patient engagement moves toward a more democratic vision of the exchange process between the physician and the patient and/or between the supply and demand for health services. In this context, the diverse actors, with their own diverse competences and subjectivities, are considered in the system in order to promote virtuous forms of dialogue and fruition of the health system in its complexity. 


\subsection{Self-management}

The verb "to manage" comes from the Latin manus (hand), which means using an instrument with one's own hands. In the medical lexicon, "self-management” means the ability of a patient to manage the symptoms, the treatments, as well as the physical, psychological, social consequences of an illness condition. This concept is also related to the achievement of an auto-regulation of a care process, strictly based on individuals' personal needs and expectations.

This state is recognized as the outcome of a process of acquisition regarding information about a disease and its implications. Thanks to this, the patient becomes autonomous in the treatment management. For this reason, the concept of "selfmanagement" evokes a representation of the exchange between the patient and the healthcare system based on the transmission of management competences and of care practices from the hospital to the everyday life contexts of the individual. Consistently, self-management becomes one possible positive outcome of a patient engagement process. Moreover, it appears to be one of the prototypical contexts in which a high engagement level manifests itself, similar to a high adherence to treatments and a profound partnership between the patient and the physician in the decision-making process about care treatments.

\subsection{Patient Empowerment}

Those ones who are familiar with a psychological literature may understand the term "empowerment". It refers to a psychological state in which the patient achieves control and power over his/her own health/disease state and possible treatments (Ajoulat et al., 2006; Feste, 1995). This state is generated within an educational process, and it is the outcome of an exchange of knowledge between the expert clinician and the patient, the latter being conceived as a passive receptor of information.

In this sense, the objective is to promote a re-acquisition of agency and self-efficacy for the patient over his/her own health. Progressively, this allows one to recover his/her autonomy after the experience of the disease onset (Anderson and Funnell, 2005).

Although this approach is related to a person-centered vision, the creators of this concept often have a solipsistic idea of the patient, as if he/she was taken out of the social context. They consider the dyadic relationship with the clinician only.

Therefore, while the concept of "empowerment" focuses on the individual in the relationship, the concept of engagement focuses on the relationship itself. Indeed, it explores the demand for care of the patient as situated into a systemic vision. Moreover, while "empowerment" is conceived as the outcome of a cognitive boosting process of the patient and of his/her health literacy level, "engagement" sustains not only the knowledge aspects of the patient's health experience, but also the emotional 
aspects related to the personal acceptance of the health condition and the behavioral skills to manage it.

In the light of these considerations, the concept of "empowerment" and the concept of "engagement" seem to be strongly connected in a reciprocal and virtuous relationship. It is possible to hypothesize that "empowerment" mediates the engagement process as an intervening factor that modulates the relationship modalities between the patient and the healthcare system.

\subsection{Patient Activation}

Considering its etymology, "activation" means "the act of initiating something" (Oxford English Dictionary, 2012). Indeed, “activation” can be understood as a process thanks to which the parts of a system are brought to an active or passive state, that is, they become able to react to stimuli. In the context of the scientific debate about the participation of patients in the process of care, the term "patient activation" refers to the level of knowledge, ability, and confidence in the patients' capacity to manage his/her own health and interact with the healthcare system (Green et al., 2012; Hibbard et al., 2005). A possible increase in the activation of patients is positively associated with the augmentation of healthy behaviors (e.g., physical exercise, diet...), adherence to the medical prescriptions, and behaviors related to information seeking for prevention purposes (Hibbard, Stockard, Mahoney, \& Tusler, 2004).

In 2004, Hibbard defined the concept of patient activation as composed of four phases. Moreover, she developed a scale to measure patient activation, which is currently the only one available in the scientific debate (PAM, Patient Activation Measure). Patients who have a minimum level of activation (level 1) tend to be passive, not aware of their own role in their health management. Level 2 refers to patients who start to adopt healthy behaviors, such as modifying their eating habits, so that they start to build their own resources and knowledge about their health condition. A level 3 patient is characterized by autonomy in the symptoms and treatments management, so that he/she is able to develop ad hoc responses to the problematic situations related to the disease. Finally, patients who are at level 4 are able to maintain their new lifestyle behaviors in the long-term, even in the context of stressful conditions.

The concept of activation features numerous elements that resemble the characteristics of the patient engagement process. Indeed, the two terms are often used synonymously in the scientific debate (Hibbard, who is the founder of the research tradition on patient activation, also uses the word "engagement" as a keyword for her works). However, according to a more careful analysis, we may see how the two concepts differ. The concept of "activation", as it is evident from the name itself, focuses mainly on the conative dimension of the behavior of the patient, and assumes that the main driver of activation is the level of knowledge of the patient about the disease 
and its management (health literacy). Moreover, there is a strong focus on the disease experience and on the management of it in the institutional context of the care (i.e., the medical consultation, the adherence to treatments, the fruition of services inside the hospital). Less attention is devoted to the "external" of the institutional hospital context and to the role of caregivers, peer network, and social context. In the end, the authors focus on the behavior of patients as a reactive response to the healthcare system and to its organizational practices. As such, the concept of patient activation is still quite passivizing (Graffigna et al., 2014; Graffigna et al., 2015).

Differently, the concept of "engagement" tries to explore the dialogue between the supply and demand of health services, considering a more inclusive spectrum of the non-institutional contexts that are important for the individual. The aspect of the everyday life of the patient, of his/her routine activities, and of the need to help them positively include the experience of disease in the wider experiential domain of his/her own life "outside the hospital", is the main driver of the patient engagement conceptualization. Indeed, the fully engaged patient becomes able to recognize him/ herself as an individual who perceives the disease as only one of the possible experiences. In virtue of this ability to adapt to the situation and to project a more sustainable lifestyle, the patient becomes able to virtuously interface with the healthcare system. Moreover, he/she becomes a real "apostle" of good engagement practices in the context of his/her own community.

To reach this level of personal maturity, the process of engagement requires an elaboration of the subjective perception of the position as a "patient", considering diverse experiential dimensions. Indeed, it is not possible to reduce these dimensions only to the cognitive and behavioral factors (which are typical of the construct of activation), but also to the emotional dimension, that is the ability of the patient to make sense of his/her own clinical condition, which is equally fundamental (as we shall discuss in the following chapter).

\subsection{Technology Engagement}

To avoid confusion, it is useful to differentiate patient engagement from another important concept. As we will argue in the next chapters, patient engagement can be easily achieved thanks to the implementation of interventions based on new technologies. In this sense, technological tools help guide a patient through a process of development that allows him/her to become fully engaged in his/her own disease and illness management. To reach this objective, patients who benefit from new technologies certainly have to be "engaged" in the use of such technologies.

However, engaging a patient in a technology use does not coincide with engaging him/her in the process of care. Technology engagement (Sharafi et al., 2006) means that one is motivated to use the technological tool, that is, he/she is genuinely curious about the tool, and he/she is able to maintain a continuous use over time. Moreover, 
technology engagement is often conceived as a phenomenon related to the concept of "flow" (see Chapter 4).

When a technological tool is used in the context of a patient engagement intervention, technology engagement would become an important aspect of ensuring that the technology-based intervention will have the expected effects. It should also be noted that the "direction" of a patient engagement intervention is always related to the process of care, regardless of whether a technology is present in the intervention.

\section{Towards a Definition of Patient Engagement: Its Relationship with Related Constructs}

To sum up, as introduced in Chapter 1, patient engagement may be considered an umbrella term that qualifies the systemic relation between the demand and the supply of healthcare at different levels and in different situations (Menichetti et al. 2015). If considered according to this meaning, patient engagement overarches the other terms that are traditionally used to denote the active role of patients in their care, such as patient adherence, patient compliance, self-management, patient involvement, patient participation, shared decision making, and patient activation (see Table 1 and Figure 1).

Discussing the connections between these traditional terms and patient engagement, the concept of "activation" has a degree of overlap with engagement, but it differs according to the breath of its consideration of the healthcare relation. The concept of "activation" is mainly limited to the attitude of patients within the institutional context of care (i.e., the Hospital, the medical consultation...) and is particularly anchored to the prototypical situation of a doctor-patient consultation.

Other concepts are strongly anchored to different prototypical situations of patient's disease management. On the one hand, "self-management", which includes the concepts of adherence and compliance, specifically refers to the behaviours that the individual is called to undertake in order for the effective application of therapeutic prescriptions to occur. These constructs (i.e., "self-management”, "adherence”, "compliance") come from a hierarchical vision of the healthcare relationship, where the healthcare provider (i.e., the expert) prescribes to the patient (i.e., the lay actor) the rules to better manage his/her disease. Due to this view of the relationship, these concepts bring a little attention to the theme of therapy negotiation. "Self-management", "adherence", and "compliance" imply that the physician is in a position of evaluation, determining whether the patient has performed well or badly, as well as whether they are able to respond adequately to the expert's requirements (Vlasnik, Aliotta, and DeLor, 2005; Haynes and Sackett, 1979).

In contrast to these traditional terms, the concept of "engagement" underlines a strong democratization of the exchange between physician and patient; thus, 


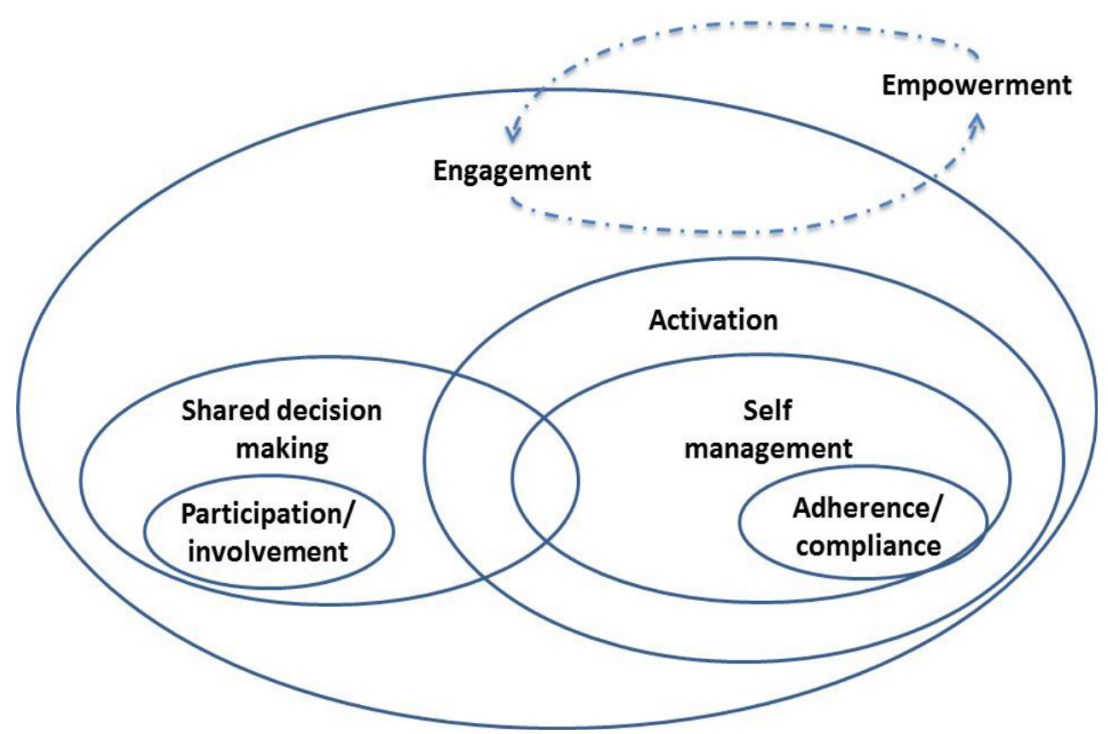

Figure 1: Patient engagement: An umbrella concept to innovate healthcare.

between the demand and supply of health services. From this perspective, different actors convey their subjectivities and their different skills to promote virtuous forms of dialogue and the better use of health services and structures.

On the other hand, "shared decision making", which includes the concepts of "involvement" and "participation", refers instead to the dyadic context of the medical consultation and the cognitive/emotional attitude of the patient in the negotiation of clinical decision-making.

The conceptual link between the concepts of "involvement”, "participation", "shared decision-making", and the concept of "engagement" is evident because they suggest the active role of patients in the process of care negotiation. Nevertheless, it is clear how these terms focus on a different level of the exchange between demand and supply of healthcare services (Murray and Gafni, 2006; Thompson, 2007).

As mentioned earlier, the concepts of "involvement", "participation", and "shared decision making" are mostly limited to the dyadic context of the exchange between doctor and patient; the concept of "engagement", instead, involves a broader and systemic context between demand and supply of health services, where medical consultation is only one of the possible levels of the analysis. An engaged patient is able to become not only an aware consumer of the traditional form of health services, but also a good promoter of best practices of health promotion in his/her social context (for example, sharing care practices in online forums and communities by advocating for patients' rights at the institutional level or by becoming founding member of a patients association).

In this framework, an exception is the concept of "empowerment", with which the concept of engagement entertains an associative relationship of mutual influence. 
Table 1: Definitions of the different concepts related to the active role of patients in healthcare

\begin{tabular}{|c|c|c|c|}
\hline Concept & Authors & Definition & Relation with engagement \\
\hline $\begin{array}{l}\text { Empower- } \\
\text { ment }\end{array}$ & $\begin{array}{l}\text { Feste, } \\
1995 \\
\text { Ajoulat et } \\
\text { al., } 2006\end{array}$ & $\begin{array}{l}\text { Empowerment suggests a position of } \\
\text { re-acquisition of agency for patients, } \\
\text { indicating a subjective sense of control } \\
\text { over their disease. } \\
\text { An empowerment-oriented approach } \\
\text { views patients as being responsible for } \\
\text { their choices and the consequences of } \\
\text { their choices. }\end{array}$ & $\begin{array}{l}\text { Empowerment entertains an } \\
\text { associative relationship of } \\
\text { mutual influence with the } \\
\text { concept of engagement. It is a } \\
\text { prerequisite for the process of } \\
\text { engagement, but in turn is fed } \\
\text { by the positive experiences that } \\
\text { the patient makes in his journey } \\
\text { of engagement }\end{array}$ \\
\hline
\end{tabular}

Activation Hibbard et The term patient activation indicates the The concept of activation preal., 2005 level of knowledge, skills, and confi- sents different degrees of overdence, implicated in the patient managing lap with engagement, in activatheir own health and interactions with the tion, however, the relation consystem of care. text is limited to the institutional and dyadic care relation between the doctor and the patient

\begin{tabular}{|c|c|c|c|}
\hline $\begin{array}{l}\text { Self- } \\
\text { manage- } \\
\text { ment }\end{array}$ & $\begin{array}{l}\text { Nakagawa- } \\
\text { kogan } \\
\text { et al., } 1988 \\
\text { Clark et al., } \\
1991\end{array}$ & $\begin{array}{l}\text { Treatment that combines biological, } \\
\text { psychological, and social intervention } \\
\text { techniques with a goal of maximising } \\
\text { the functioning of regulatory processes, } \\
\text { basing on the patients' own beliefs and } \\
\text { expectations. } \\
\text { The term also refers to day to day tasks } \\
\text { an individual must undertake to control or } \\
\text { reduce the effect of disease on physical } \\
\text { health status with the collaboration or } \\
\text { the guidance of a health provider. These } \\
\text { behaviors also require sufficient know- } \\
\text { ledge of the condition and its treatments. }\end{array}$ & $\begin{array}{l}\text { Engagement defines the } \\
\text { exchange between patient } \\
\text { and health care system, not } \\
\text { only in terms of the transfer of } \\
\text { knowledge and skills focused } \\
\text { on purely managerial aspects } \\
\text { of the care. Moreover, it does } \\
\text { not reduce the exchange to the } \\
\text { context of the dyadic relation- } \\
\text { ship between doctor-patient and } \\
\text { it mainly refer to an individual } \\
\text { context of care }\end{array}$ \\
\hline dherence & $\begin{array}{l}\text { Vlasnik } \\
\text { et al., } 2005 \\
\text { Robinson, } \\
2008\end{array}$ & $\begin{array}{l}\text { The term adherence refers to the patient's } \\
\text { ability to follow treatment recommen- } \\
\text { dations. It is considered a key factor in } \\
\text { improving the patient's quality of life and } \\
\text { reducing costs. }\end{array}$ & $\begin{array}{l}\text { Adherence describes a more } \\
\text { democratic version of the } \\
\text { process of exchange between } \\
\text { doctor and patient. It too, refers } \\
\text { to an individual context of care }\end{array}$ \\
\hline $\begin{array}{l}\text { ompli- } \\
\text { ice }\end{array}$ & $\begin{array}{l}\text { Haynes, } \\
1979 \\
\text {-Fletcher, } \\
1989\end{array}$ & $\begin{array}{l}\text { The extent to which a person's behavior } \\
\text { (in terms of taking medications, following } \\
\text { diets, or executing lifestyle changes) coin- } \\
\text { cides with medical or health advice. } \\
\text { In other words, it refers to patients doing } \\
\text { what the health professionals want them } \\
\text { to do. }\end{array}$ & $\begin{array}{l}\text { Engagement goes beyond the } \\
\text { specific assessment of the beha- } \\
\text { vior and attitude of the patient } \\
\text { towards the requirements of the } \\
\text { clinician. Compliance thus refers } \\
\text { to a more narrowed individual } \\
\text { context of care }\end{array}$ \\
\hline
\end{tabular}


continued Table 1: Definitions of the different concepts related to the active role of patients in healthcare

\begin{tabular}{|c|c|c|c|}
\hline Concept & Authors & Definition & Relation with engagement \\
\hline $\begin{array}{l}\text { Shared } \\
\text { decision } \\
\text { making }\end{array}$ & $\begin{array}{l}\text { Murray et } \\
\text { al., } 2006 .\end{array}$ & $\begin{array}{l}\text { Doctors might encourage patients to seek } \\
\text { and read information from other sources } \\
\text { and to discuss this at subsequent encoun- } \\
\text { ters. Doctors may also need to help } \\
\text { patients to interpret information obtained } \\
\text { from other sources. }\end{array}$ & $\begin{array}{l}\text { These terms describe a more } \\
\text { negotiating role of the patient in care } \\
\text { management, but the concept of } \\
\text { engagement involves a broader and } \\
\text { systemic context between demand } \\
\text { and supply of health services, where }\end{array}$ \\
\hline $\begin{array}{l}\text { Involve- } \\
\text { ment and } \\
\text { participa- } \\
\text { tion }\end{array}$ & $\begin{array}{l}\text { Entwistle } \\
\text { and Watt, } \\
2006 \\
\text { Thompson, } \\
2007\end{array}$ & $\begin{array}{l}\text { Involvement and participation are used } \\
\text { as interchangeable terms and describe } \\
\text { the relationship between patient (lay) and } \\
\text { health provider (expert) in the process of } \\
\text { clinical decision-making. }\end{array}$ & $\begin{array}{l}\text { medical consultation is only one } \\
\text { of the possible levels of analysis. } \\
\text { Involvement and participation mainly } \\
\text { refer to a dyadic context of care }\end{array}$ \\
\hline
\end{tabular}

The concept of empowerment connotes a position of agency for patients. It is made possible through re-acquisition of the subjective sense of control over their disease (Aujoulat, d'Hoore, and Deccache, 2007). It is a prerequisite for the process of engagement fed by the positive experiences that the patient gains on his/her journey of exchange between the demand and supply within the healthcare system.

\section{Conclusions}

In this chapter, we discussed various terms and concepts that are populating current debates about patients' active role in healthcare. Our aim was offering a preliminary glossary of the different concepts in order to lay groundwork and forward from the confusion that this plethora of terms might provoke. Only by agreeing on a shared conceptualization and definition of different concepts will be possible to realistically set healthcare innovation goals and build concrete guidelines to achieve them.

Furthermore, this analysis of the different concepts related to patients' active role in healthcare offers us the possibility to better shape the margins of the engagement concept by also highlighting its traits of innovativeness and, on the contrary, its continuities with other more classical conceptualizations used in the healthcare domain.

Based on these premises, the following chapter will propose a concrete framework to make sense of the potentialities of the engagement process and its applicability to innovate health and care. 


\section{References}

Anderson, E.B. (2002). Patient-centeredness: a new approach. Nephrology news \& issues, 16(12), $80-82$.

Anderson, R.M., \& Funnell, M.M. (2010). Patient empowerment: myths and misconceptions. Patient Education and Counseling, 79(3), 277-282.

Anderson, Robert M., \& Martha M., Funnell. (2005). Patient empowerment: reflections on the challenge of fostering the adoption of a new paradigm. Patient Education and Counseling, 57(2), 153-157.

Aujoulat I., D'Hoore W., Deccache A. (2007) Patient empowerment in theory and practice: polysemy or cacophony?. Patient Education and Counseling, 66(1), 13-20.

Barello, S., Graffigna, G., Savarese, M. , Bosio, A.C. (2014) Engaging patients in health management: towards a preliminary theoretical conceptualization. Psicologia della Salute, 3, 11-33

Barello, S., Graffigna, G.(2014) Engaging patients to recover life projectuality: An Italian crossdisease framework. Quality of Life Research. (in press) 10.1007/s11136-014-0846-x

Barello, S., Graffigna, G., Vegni, E., Bosio, A.C. (2014) The challenges of conceptualizing patient engagement in healthcare: a lexicographic literature review. Journal of Participatory Medicine, 6, e9.

Charles, C., Gafni, A., \& Whelan, T. (1999). Decision-making in the physician-patient encounter: revisiting the shared treatment decision-making model. Social Science \& Medicine, 49(5), 651-661.

Charles, C., Gafni, A., \& Whelan, T. (2000). How to improve communication between doctors and patients: Learning more about the decision making context is important. BMJ: British Medical Journal, 320(7244), 1220.

Di Matteo, M.R. (2004). Evidence-based strategies to foster adherence and improve patient outcomes. JAAPA: Official Journal of the American Academy of Physician Assistants, 17(11), 18.

Dyson, E. (2009). Why participatory medicine?. Journal of Participatory Medicine, 1(1),1.

Entwistle, V.A., \& Watt, I.S. (2006). Patient involvement in treatment decision-making: the case for a broader conceptual framework. Patient Education and Counseling, 63(3), 268-278.

Evangelista, L.S. (1999). Compliance: a concept analysis. In Nursing forum, (Vol. 34, No. 1, pp. 5-12). Blackwell Publishing Ltd.

Feste C., Anderson R.M. (1995). Empowerment: from philosophy to practice. Patient Education and Counseling, 26, 139-144.

Fletcher, R.H. (1989). Patient compliance with therapeutic advice: a modern view. The Mount Sinai journal of medicine, New York, 56(6), 453-458.

Gallant, M.H., Beaulieu, M.C., \& Carnevale, F.A. (2002). Partnership: an analysis of the concept within the nurse-client relationship. Journal of Advanced Nursing, 40(2), 149-157.

Graffigna G., Barello S., Bonanomi A. and Lozza E (2015) Measuring patient engagement: development and psychometric properties of the Patient Health Engagement (PHE) Scale. Front. Psychol. 6:274. doi: 10.3389/fpsyg.2015.00274

Graffigna, G., Barello, S., Libreri, C., Bosio, A.C. (2014) How engaging type-2 diabetic patients in their health management? Implications for clinical practices. BMCPublicHealth,14(1), 648.

Greene, J., \& Hibbard, J.H. (2012). Why does patient activation matter? An examination of the relationships between patient activation and health-related outcomes. Journal of General Internal Medicine, 27(5), 520-526.

Haynes, R.B., \& Sackett, D.L. (1979). Compliance in health care. Johns Hopkins University Press.

Hibbard, J.H., \& Tusler, M. (2005). How much do health literacy and patient activation contribute to older adults' ability to manage their health?. AARP Public Policy Institute, (pp. 2005-05). Washington, DC. 
Hibbard, J.H., Mahoney, E.R., Stockard, J., \& Tusler, M. (2005). Development and testing of a short form of the patient activation measure. Health Services Research, 40(6p1), 1918-1930.

Hibbard, J.H., Stockard, J., Mahoney, E.R., \& Tusler, M. (2004). Development of the Patient Activation Measure (PAM): conceptualizing and measuring activation in patients and consumers. Health Services Research, 39(4p1), 1005-1026.

Kabat-Zinn, J. (2000). Participatory medicine. Journal of the European Academy of Dermatology and Venereology, 14(4), 239-240.

Marteau, T.M., \& Dormandy, E. (2001). Facilitating informed choice in prenatal testing: how well are we doing?. American Journal of Medical Genetics, 106(3), 185-190.

Menichetti J, Libreri C, Lozza E, Graffigna G. Making patients protagonists of their own care: $A$ bibliometric analysis of the ongoing literature debate. HealthExpectations. 2015 doi: 10.1111/ hex.12299.

Murray E., Charles C., Gafni A. (2006) Shared decision-making in primary care: tailoring the Charles et al. model to fit the context of general practice. Patient Education and Counseling, 62, 205-211.

O’Connor, A.M., Rostom, A., Fiset, V., Tetroe, J., Entwistle, V., Llewellyn-Thomas, H., ... \& Jones, J. (1999). Decision aids for patients facing health treatment or screening decisions: systematic review. BMJ: British Medical Journal, 319(7212), 731-734.

Pianigiani, O. (1988). Dizionario etimologico della lingua italiana. I Dioscuri.

Playle, J.F., \& Keeley, P. (1998). Non-compliance and professional power. Journal of advanced nursing, 27(2), 304-311.

Sharafi, P., Hedman, L., \& Montgomery, H. (2006). Using information technology: engagement modes, flow experience, and personality orientations. Computers in Human Behavior, 22(5), 899-916.

Stewart, M. (2001). Towards a global definition of patient centred care: the patient should be the judge of patient centred care. BMJ: British Medical Journal, 322(7284), 444.

Thompson, A., G. (2007) The meaning of patient involvement and participation in health care consultations: a taxonomy. Social Science \& Medicine, 64, 1297-1310.

Thompson, I., Thrasher, J.B., Aus, G., Burnett, A.L., Canby-Hagino, E.D., Cookson, M.S., ... \& Tangen, C.M. (2007). Guideline for the management of clinically localized prostate cancer: 2007 update. The Journal of Urology, 177(6), 2106-2131.

Thorpe, K.E. (2005). The rise in health care spending and what to do about it.

Health Affairs, 24(6), 1436-1445.

Vlasnik J.J., Aliotta S.L., DeLor B. (2005). Medication adherence: factors influencing compliance with prescribed medication plans. The Case Manager, 16, 47-51.

Weitzel, M., Smith, A., Lee, D., de Deugd, S., \& Helal, S. (2009). Participatory medicine: leveraging social networks in telehealth solutions. In Ambient Assistive Health and Wellness Management in the Heart of the City, (pp. 40-47). Springer Berlin Heidelberg. 